\title{
PESTE SUÍNA CLÁSSICA: MONITORAMENTO DO STATUS SANITÁRIO DOS SUÍNOS EM PROPRIEDADES DA ZONA SUL DO RIO GRANDE DO SUL
}

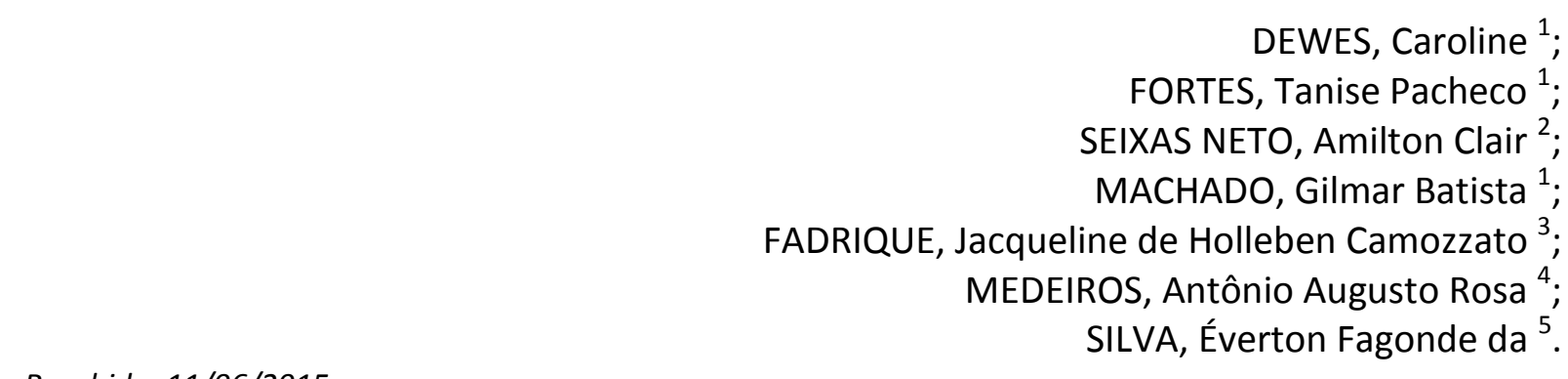

Recebido: $11 / 06 / 2015$

Aceito: 05/05/2016

${ }^{1}$ Pós-Graduando do Programa de Pós-Graduação em Veterinária da UFPEL; ${ }^{2}$ PNPD do Programa de PósGraduação em Veterinária da UFPEL; ${ }^{3}$ Médica Veterinária do SEAPA; ${ }^{4}$ Fiscal Estadual Agropecuário do SEAPA; ${ }^{5}$ Professor da Faculdade de Veterinária da UFPEL.

\section{RESUMO}

A peste suína clássica (PSC) é uma enfermidade multissistêmica que acomete os suínos. A doença é altamente contagiosa, trazendo prejuízos socioeconômicos e sanitários graves, dificultando ou impossibilitando o comércio internacional de animais e produtos de origem animal. $\mathrm{O}$ trabalho teve como objetivo realizar a vigilância sanitária em cinco municípios da zona sul do Rio Grande do Sul.

Palavras-chave: Carne. Carcaça. Exportação. Status sanitário.

A peste suína clássica (PSC) é uma enfermidade altamente contagiosa e de difícil combate em áreas de alta concentração de suínos (RIDPATH; FLORES, 2007). A doença é causada por um Pestivírus da família Flaviviridae, podendo acometer animais de todas as idades (FREITAS et al., 2007; PENRITH et al., 2011). A transmissão pode ocorrer através do contato com animais silvestres, instalações, água, instrumentos utilizados no manejo dos animais, veículos, roupas, calçados e pelo ar entre criações vizinhas durante o surto em áreas de alta densidade populacional (OIE, 2012; OLIVEIRA et al., 2014). O primeiro surto de PSC no mundo foi descrito nos Estados Unidos em 1833. No Brasil, a primeira descrição da enfermidade foi realizada no estado de Minas Gerais em 1899 (HANSON, 1957). 
Para executar o monitoramento e controle da PSC, o serviço veterinário oficial deve contar com estrutura operacional adequada e pessoal treinado em emergência sanitária. Ao mesmo tempo, a conscientização da população sobre a doença facilita a implantação de medidas para impedir a criação de suínos em lixões e a utilização de restos alimentares como ração. Nos animais positivos deve ser realizado o abate sanitário por médicos veterinários do serviço oficial procedendo assim à cremação ou enterramento das carcaças. Além destes cuidados, uma medida fundamental é a introdução de animais sentinelas após a realização do vazio sanitário (MAPA, 2004).

Em 2001, através da Instrução Normativa n. 1, o Ministério da Agricultura, Pecuária e Abastecimento (MAPA), aprovou as normas para ingresso de suídeos, de seus produtos e subprodutos na Zona Livre de Peste Suína Clássica, constituída pelos estados do Rio Grande do Sul, Santa Catarina, Paraná, São Paulo, Minas Gerais, Mato Grosso, Mato Grosso do Sul, Goiás, Tocantins, Rio de Janeiro, Espírito Santo, Bahia, Sergipe e Distrito Federal (MAPA, 2001). Atualmente, o Rio Grande do Sul e Santa Catarina são reconhecidos internacionalmente como áreas livres de PSC (OIE, 2015).

Este trabalho foi realizado em 22 propriedades localizadas na região sul do Rio Grande do Sul, selecionadas através de amostragem aleatória, seguindo o cronograma do Plano de Contingência para o diagnóstico de PSC no Estado (Tabela 1). A média de suínos coletados por propriedade foi de 8,22 .

Tabela 1 - Número de propriedades avaliadas por município da região sul do estado do Rio Grande do Sul.

\begin{tabular}{cc}
\hline Município & Número de propriedades \\
\hline São Lourenço do Sul & 7 \\
Canguçu & 9 \\
Turuçu & 1 \\
Jaguarão & 1 \\
Santana da Boa Vista & 4 \\
\hline TOTAL & $\mathbf{2 2}$ \\
\hline
\end{tabular}


Foram coletadas 181 amostras de sangue através de punção da veia cava cranial, utilizando seringa estéril com agulha $100 \times 20 \mathrm{~mm}$ (Figura 1). O material coletado foi colocado em tubos identificados com o número, a idade e o sexo de cada animal. As amostras, sob refrigeração, foram encaminhadas para a Inspetoria Veterinária e Zootécnica (IVZ) de Pelotas para centrifugação, separação do soro, congelamento e posterior envio para o Laboratório de Apoio Animal (LAPA) em Recife. No LAPA foram realizados os testes de imunofluorescência direta, isolamento viral em cultivo celular, ELISA e neutralização viral, conforme sugerido pelo Plano de Contingência para a Peste Suína Clássica (MAPA, 2004).

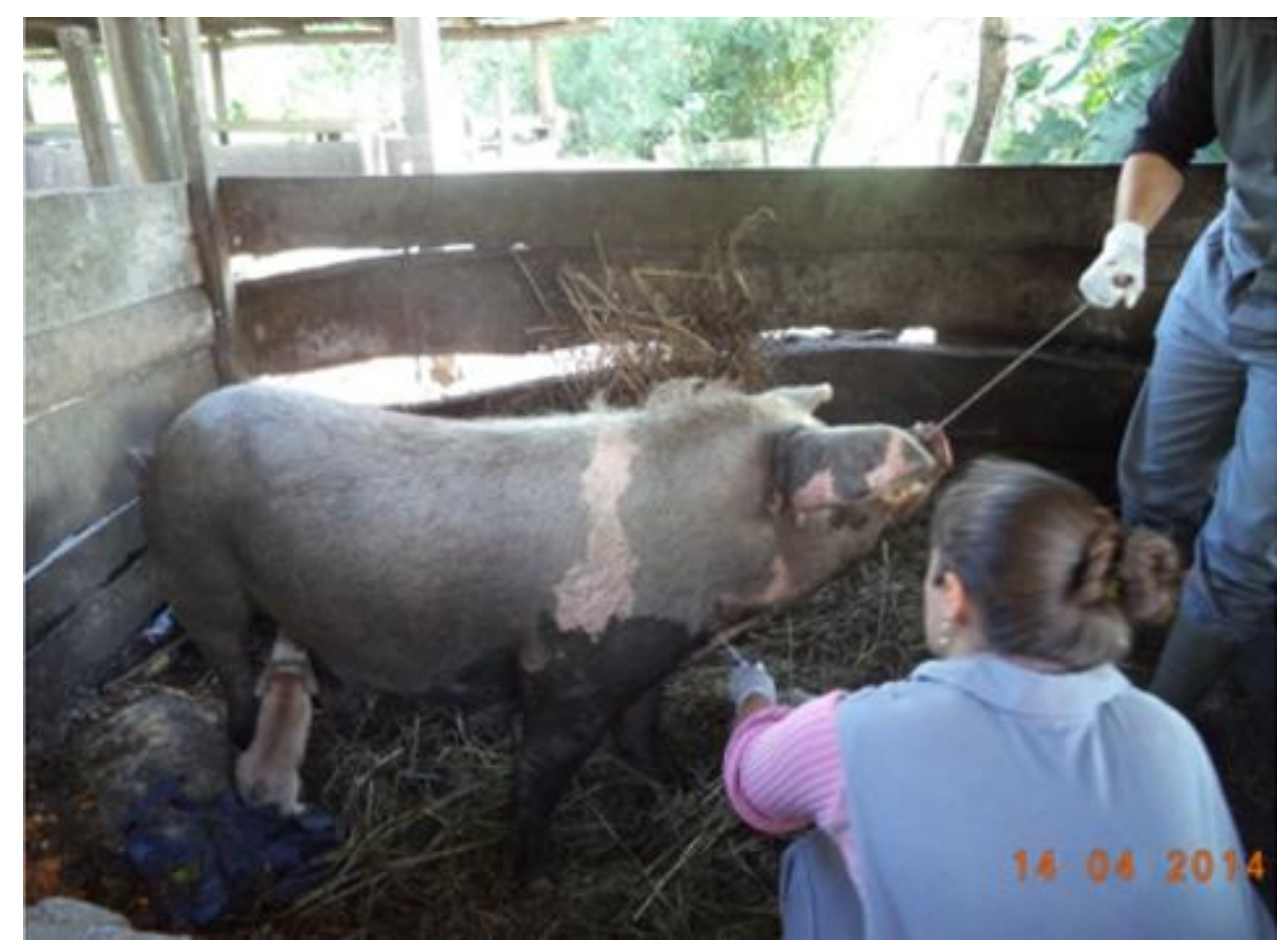

Figura 1 - Colheita de sangue através de punção da veia cava cranial.

Todas as 181 amostras coletadas mostraram-se negativas para a PSC. Segundo o MAPA (2004), zonas livres da doença como o Rio Grande do Sul, contam com um sistema de vigilância sanitária que tem o objetivo de impedir o ingresso e detectar de forma precoce a reintrodução do vírus, garantindo a manutenção do status sanitário alcançado pelo Estado.

As medidas de vigilância sanitária são importantes, pois, conforme relatam Penrith et al. (2011), a erradicação não pode ser aceita como um estado permanente e a falta de áreas vizinhas infectadas não garante proteção contra a introdução do vírus por animais 
provenientes de áreas distantes. A introdução inesperada do vírus em regiões livres de PSC pode permitir uma disseminação da enfermidade quando animais são transportados para outras propriedades ou para o abatedouro, de modo geral, uma demora no reconhecimento da enfermidade é altamente provável. Assim, a monitoria sanitária é uma ferramenta importante para o conhecimento do perfil sanitário de uma granja sendo um dos componentes capazes de garantir que a produção não sofra influência negativa das doenças e assegurar bons índices produtivos (BARCELLOS et al., 2009; RISTOW, 2007).

O diagnóstico negativo para os 181 animais das 22 propriedades analisadas indica que as estratégias propostas pelo Plano de Contingência para a PSC são eficazes. Entretanto, para que o estado do Rio Grande do Sul continue usufruindo do status sanitário alcançado, é importante que medidas como o controle rigoroso da movimentação de animais entre as granjas e as investigações sorológicas continuem sendo realizadas.

\section{CLASSICAL SWINE FEVER: MONITORING THE SANITARY STATUS OF PIGS IN PROPERTIES FROM THE SOUTH OF RIO GRANDE DO SUL}

\section{ABSTRACT}

lassical swine fever (CSF) is a multisystemic disease that affects pigs. The disease is highly contagious, bringing socio-economic and sanitary losses, hampering or hindering the international trade of animals and their products. The study aimed to analyze the sanitary surveillance in five cities of the southern region of Rio Grande do Sul.

Keywords: Meat. Carcass. Export. Sanitary status.

\section{PESTE PORCINA CLÁSICA: SEGUIMIENTO DEL ESTADO SANITARIO DE LOS SUINOS EN PROPIEDADES DE LA ZONA SUR DE RIO GRANDE DO SUL}

\section{RESUMEN}

a peste porcina clásica (PPC) es una enfermedad multisistémica que afecta a los cerdos. La enfermedad es muy contagiosa, acarreando perjuicios económicos y sanitarios graves, dificultando o imposibilitando el comercio internacional de animales y productos de origen animal. El estudio tuvo como objetivo llevar a cabo la vigilancia sanitaria en cinco municipios del sur de Rio Grande do Sul.

Palabras clave: Carne. Carcasa. Exportación. Estatus sanitario. 


\section{REFERÊNCIAS}

BARCELLOS, D. E. S. N.; MARQUES, B. M. F. P. P.; MORES, T. J.; CENTENARO, F.;

SOBESTIANSKY, J. Uso de perfis sorológicos e bacteriológicos em suinocultura. Acta Scientiae Veterinariae, v. 37, p. 117-128, 2009.

MAPA, Ministério da Agricultura, Pecuária e Abastecimento. Instrução Normativa n. 1, de 4 de janeiro de 2001. Normas para ingresso de suídeos, seus produtos e subprodutos na Zona Livre de Peste Suína Clássica. In: Diário Oficial da União, Brasília, seção 1, p. 6, 16 jan. 2001.

MAPA, Ministério da Agricultura, Pecuária e Abastecimento. Instrução Normativa n. 27, de 20 de abril de 2004. Plano de Contingência para a Peste Suína Clássica. In: Diário Oficial da União, Brasília, seção 1, p. 7, 27 abr. 2004.

FREITAS, T. R. P.; ESTEVES, E. G.; OLIVEIRA, A. M.; JOINEAU, M. E. G.; DUARTE, A. C. S.; VARGAS, I.; CALDAS, L. A.; REBELLO, M. A. Classical Swine Fever in Brazil: study for the survey of classical swine fever outbreaks in Brazil from 1978 to 2004. Semina, v. 28, n. 2, p. 277286, 2007.

HANSON, R. P. The origin of the Hog Cholera. Journal of the American Veterinary Medical Association, v. 131, n. 5, p. 211-218, 1957.

OIE. World Organization for Animal Health. Classical Swine Fever (Hog Cholera), 2012. Disponível em:

<http://www.oie.int/fileadmin/Home/eng/Animal_Health_in_the_World/docs/pdf/CLASSIC AL_SWINE_FEVER_FINAL.pdf> Acesso em: 01 de junho de 2015.

OIE. World Organisation for Animal Health. List of CSF free Member Counties, 2015. Disponível em: <http://www.oie.int/en/animal-health-in-the-world/official-diseasestatus/classical-swine-fever/list-of-csf-free-member-countries/> Acesso em 07 de junho de 2015.

OLIVEIRA, L. G.; OLIVEIRA, M. E. F.; GATTO, I. R. H.; ALMEIDA, H. M. S.; SAMARA, S. I. Peste Suína Clássica: Caracterização da Enfermidade e Ações de Controle e Erradicação adotadas no Brasil. Revista Veterinária e Zootecnia, v. 21, n. 3, p. 343-358, 2014.

PENRITH, M. L.; VOSLOO, W.; MATHER, C. Classical Swine Fever (Hog Cholera): Review of Aspects Relevant to Control. Transboundary and Emerging Diseases, v. 58, p. 187-196, 2011.

RIDPATH, J. F.; FLORES, E. F. Flaviviridae. In: FLORES; E. F. Virologia Veterinária. Santa Maria: Ed. da UFSM, 2007. Cap. 22, p. 565-591.

RISTOW, L. E. Monitoramento global da sanidade de granjas de suínos. In: SIMPÓSIO INTERNACIONAL DE PRODUÇÃO SUÍNA, 3, 2007, Águas de Lindóia. ANAIS. Águas de Lindóia, 2007, p. 50-56. 
Autor para correspondência: Caroline Dewes.

Grupo de Estudos em Doenças Transmitidas por Animais (GEDTA), Faculdade de Veterinária, Universidade Federal de Pelotas, Campus Universitário, Capão do Leão (RS), CEP 96160-000. caroldewesvet@hotmail.com 